\title{
SOCIAL MEDIA AND SOCIAL CAPITAL IN ONLINE LEARNING
}

\author{
A. Venter \\ University of Johannesburg \\ South Africa \\ e-mail:ventea@unisa.ac.za
}

\section{ABSTRACT}

Online learning inherently affords collaborative learning opportunities for participating students. Open distance learning (ODL) institutions typically accommodate students from diverse educational backgrounds with disparate levels of access to technological resources. The mere existence of an online learning platform does not necessarily equate to student access to collaborative learning opportunities. A qualitative study investigated how diverse students in an online learning module collaborated with peers in furthering their learning project at a large ODL university. It emerges that students engage in various formal and informal collaborative learning activities which constitute the creation of personal learning environments (PLEs). PLEs demonstrate the role of student agency as students coordinate their options. Social capital theory shows how different types of social ties in PLEs provide for bonding and bridging social capital; the combination of which serves the learning project by providing for both strong ties in supportive relationships between students and weak ties with knowledge generation capabilities between previously unacquainted students. The results can assist online learning practitioners who wish to promote beneficial collaborative learning opportunities among their students.

Keywords: online learning, collaborative learning, Personal Learning Environment, bonding social capital, bridging social capital

\section{INTRODUCTION}

Online learning affords participating students the opportunity to interact with one another regardless of background, location or time. The application of collaborative online learning potentially provides a social space for diverse students to establish a learning network. Such a learning network provides a platform for students from different locations and backgrounds to develop social capital as they learn together and build relations and trust (Oztok et al. 2015, 19).

However, such interactions are determined by affordability, preferred time slots and platforms of choice as students may demonstrate disparate levels of access to the requisite online technologies and skills (Queiros and De Villiers 2016). As a result, students may experience different levels of disconnectedness and isolation in their online studies. The establishment of mutually beneficial interactions between online students require a flow of 
information and shared feelings of purpose, reciprocity and trust. For these reasons, ODL institutions need to determine whether their learning strategies and platforms enable students to have mutually beneficial relationships and develop social capital that support their learning goals.

This study is directed at exploring the role of social capital development in online learning in view of the challenges mentioned above. A qualitative research approach was conceptualised to study online students' experiences and perceptions of collaborative online learning. The research was conducted among a sample of students registered for a fully online module at Unisa, a large ODL institution in South Africa. The article will describe the results of the study and discuss how the students responded to the demands of collaborative online learning. The discussion will demonstrate how the students engaged in peer interaction and formed different types of social ties and learning networks in order to mitigate the challenges of their online studies.

The article directs the attention to student participation in extended formal and informal learning networks; they form different types of social ties and customise their learning activities to create PLEs. The theory of social capital is applied to explain the development of close ties with bonding social capital and weak ties with bridging social capital to facilitate collaborative learning experiences for diverse students.

The intent is not to describe the overall architecture of comprehensive social learning networks nor to establish any causality between student collaborations and academic performance. The article is also not concerned with the dark side of student collaborations. Although the study points towards the potential of some racial differences in online collaborations, the analysis is not concerned with social justice issues but attempts to explore the scope of student collaborations as they deal with the demands of online learning.

\section{LITERATURE OVERVIEW}

The inherent interactive affordances of the internet and the accompanying advances in collaborative online learning pedagogies provide for the establishment of a social learning space where students engage in interaction and dialogue and establish a network of learning. Such collaborations pave the way for creating histories of learning together, sharing resources and building trust and belonging, regardless of background or location. Online students can work together to obtain benefits not necessarily or readily available to them in their individual capacities (Lin 1999, 31; Narayan and Pritchett 1999, 873-874).

The online learning landscape in South Africa features divergent levels of student access to online technologies, including devices, internet access and relevant online learning skills. 
These discrepancies are relevant in the case of Unisa as a large number of its students have limited access to such requisite technologies and skills due to their socio-economic and educational backgrounds. These students experience challenges in achieving success in their online studies. This is significant in the Unisa context because limited access to educational resources accompanies low literacy levels that contributes towards the marginalisation of struggling students by underscoring the digital divide (Kajee 2008, 216-217; Bharuthram and Kies 2013, 415; Queiros and De Villiers 2016, 174). It should be noted that other Unisa students come from higher social-economic and privileged educational backgrounds and are academically strong and technologically savvy. These students claim to esteem online learning and purportedly appreciate the benefits associated with online learning (Queiros and De Villiers 2016,166). The unequal levels of access to requisite resources have a bearing on online students' connectedness and compromise the opportunities they have to participate in the online learning experiences.

In addition, online learning communities are not static, or coherent or even homogeneous and this exacerbates the challenge of online participation and collaboration among online students. Typically, online groups share a zero-history as they are most probably strangers and don't necessarily share the same interests (Oztok et al. 2015, 20). The risk posed by low levels of connectedness between students leads to challenges for meaningful collaboration and social capital development among online students. The concern for ensuring parity in delivering collaborative online learning benefits for students is real.

The theory of social capital is useful to study the manner in which people develop relationships and establish connections in learning networks. Social capital theory explains how the development of "mutual acquaintance and recognition" between people support the sharing of resources between them (Bourdieu 1986, 249). Social capital refers to the inherent qualities and subsequent benefits that exist in or between social groups or networks due to the interaction among its members (Coleman 1988).

In reality, the existence of student interconnections is no guarantee that social capital will develop. Beneficial social ties only come to fruition when there is a flow of information and reciprocity and trust can develop between the relationship partners (Putnam 2001; Oztok et al. $2015,20)$.

Different dimensions of social capital present in an online learning environment, namely structural, relational and cognitive opportunities to collaborate and share experiences and resources (Wasko and Faraj 2005; Cummings, Heeks and Huysman 2006; Chiu, Hsu and Wang 2006). These three categories relate to opportunities to collaborate (structural), opportunities to develop shared norms and reciprocity (relational) and opportunities to share meaning and sense- 
making (cognitive).

The structural dimension includes the history, extent and ways in which it is possible for an individual to connect with others on the network and gain benefits from the social capital transactions (Adler and Kwon 2002, 24). The relational dimension of social capital refers to the norms and values that develop in the relationships between the participants. It becomes possible to develop and maintain trust and measures of reciprocity when there are personal and on-going relationships between the people in a network (Nahapiet and Ghoshal 1998, 244; Daniel, Schwier and McCalla 2003). Cognitive social capital concerns the sharing of meaning and sense-making through shared language, codes and narratives. Sharing stories bind people together and absence of sharing promote indifference (Nahapiet and Ghoshal 1998, 244). Opportunity, motivation and ability to collaborate are key ingredients for the development or accumulation of social capital in online learning settings (Adler and Kwon 2002, 24-27; Nahapiet and Ghoshal 1998, 251). This implies that students discharge their social capital supply differently and therefore the potential exists for different types of relationships within and between networks (Oztok et al. 2015, 20).

\section{BONDING SOCIAL CAPITAL IN ONLINE LEARNING}

When people share similarities in any way, such as sharing biographical characteristics (i.e. race, gender, language) or life goals (i.e. obtaining a qualification, working hard), it becomes possible for them to establish close ties. In this way it is possible for students who share similar interests to develop close ties. The concept of bonding social capital applies as it describes the process during which close ties emerge between individuals who are relatively homogenous and share feelings of closeness and belonging. The establishment of such bonds support the development of social cohesion and social and/or emotional support. Strong ties between friends affords exclusive opportunities for social capital development and this can be described as "network closure" (Burt 2004, 351).

Members with close ties typically have frequent interactions and this fosters mutual appreciation of collaboration. The premium placed on collaboration helps them to learn from one another, even if it contains negative reviews or comments. The development of bonding social capital in close ties provides for supportive relationships and the exclusive sharing and exchange of relevant information and resources (Carceller, Dawson and Lockyer 2015, 15; Oztok, Zingaro and Makos 2013, E204; Oztok et al. 2015, 20).

\section{BRIDGING SOCIAL CAPITAL IN ONLINE LEARNING}


It is possible for students to connect and interact with a wide range of students and establish widespread or loose ties with those students. These ties are regarded as weak ties by virtue of being sporadic or once-off. These weak or loose ties function as bridges between strangers, and provide alternative paths to non-redundant information and opinions. Weak ties potentially close the gap between previously unacquainted students. The concept bridging social capital explains the beneficial role of widespread and/or shallow ties between people from different walks of life (Valenzuela, Park and Kee 2009, 880). The strength of weak ties do not lie in any form of familiarity embedded in the ties but is founded on the ability to close social distances and facilitate "betweenness" between previously unconnected people (Granovetter 1973, 1360, 1363).

Weak, loose, shallow or wide ties have bridging social capital potential (Steinfeld, Ellison and Lampe 2008, 436; Oztok et al. 2015, 20). Bridging social capital can be regarded as indispensable for facilitating the establishment of communication pathways between students who would otherwise not have had the opportunity to collaborate. The establishment of ties between online students is essential or communication between them as online students are typically quite diverse. Online students don't get together in online groups because they are acquainted with one another and even share similar interests, but because they are registered for the same course (Oztok 2012, 5).

The possibility of disconnections or gaps between the people in distributed groups or networks represent the phenomenon of "structural holes". Structural holes can be overcome by "brokers" who connect previously unacquainted people and diffuse information across gaps in the broader learning network. The concept of structural holes challenges a traditional notion that only strong ties are important for effective collaborations between students. The proposed alternative is that weak ties have brokering potential which is critical in exposing students to new knowledge or fresh ideas. This type of interaction with diverse students is not possible when strong ties dominate due to "relational inactivity and cognitive lock-in" (Chen, Choi and $\mathrm{Yu} 2012,80$ ). One of the possible side-effects of such structural closure is the potential to inhibit new ideas. Students have a greater chance of having good ideas when they stand near gaps or holes in a network and are exposed to diverse opinions and resources from the outside world (Burt 2004, 351). In this way, structural holes and network diversity present fertile ground for the development of innovation, the generation of new knowledge production and the facilitation of learning outcomes (Chen et al. 2012, 80).

It follows that individuals with a large number of connections in diverse network have potentially greater access to social capital than those who are connected to smaller or less distributed networks (Valenzuela et al. 2009, 877). Larger networks occasion more opportunities for students to connect with a wide range of people. More interactions provide 
more opportunities to obtain feedback from peers and this stimulate improved performance due to exposure to alternative viewpoints and a broad spectrum of resources (Casquero et al. 2016, 64-65). A bigger supply of cognitive capacity affords for task division and sharing between members (Kirschner 2009,14). This holds a distribution advantage as learning in collaborative setting capacitates students to overcome their individual limitations.

\section{PERSONAL LEARNING ENVIRONMENTS (PLES)}

A basic tenet of collaborative online learning is that learning involves individual and social learning processes to run concurrently as the student interacts with people and technology. It can be described as an "in the head" phenomenon that takes place in a social context (Oztok et al. 2015, 19). People learn throughout their lives and for different reasons and it can take place in various kinds of environments and contexts. Formal learning constitutes but one part of the overall learning process. This engendered the conceptualisation of a PLE as an all-inclusive and collaborative learning space as students move within and across different learning platforms. PLEs serve as a portal to the world with flexible access to people and resources worldwide, including informal and formal learning networks (Downes 2007). Self-initiated interactions on an informal network happen alongside mandatory interactions on formal learning networks (Dawson 2010, 736). Informal learning augment formal learning as students transfer connections and resources across their integrated networks in PLEs and develop a type of collective expertise (Attwell 2007).

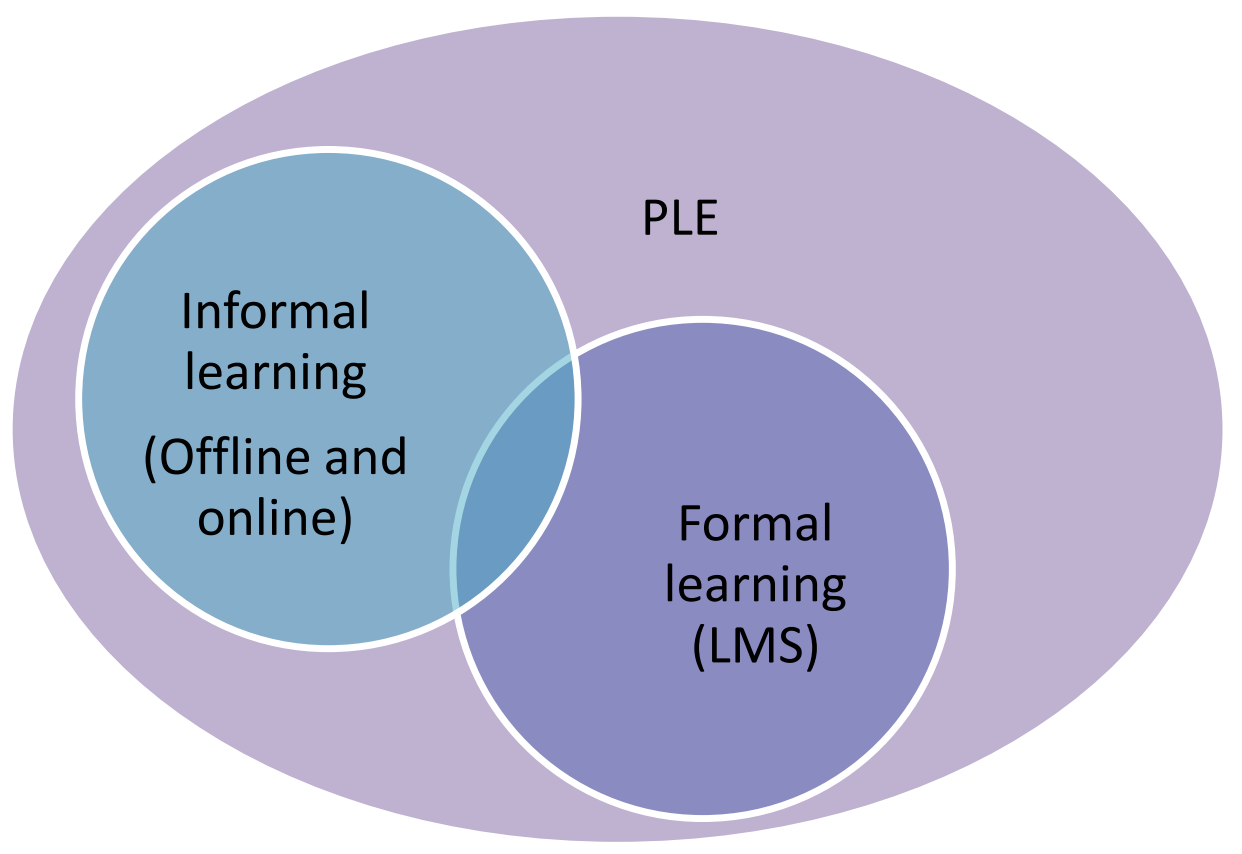

Figure 1: Illustration of the integration of formal and informal learning in a PLE 
PLEs provide a single window from which students can source, edit, share, track and monitor their own learning activities, while following and collaborating with others (Chen et al. 2012, 77). It offers a space for the integration of offline and online tools, platforms or networks (Van Harmelen 2006).

While the formal and informal learning networks exist independently of each other, they intersect when students engage with one another to further their studies. Each PLE grows organically according to students' needs and circumstances. Students manage, coordinate and regulate the formal and informal learning options available to them in a PLE. PLEs encapsulate an integration of both individual and social learning dimensions in an online learning environment.

\section{RESEARCH METHODOLOGY}

ODL institutions such as Unisa need to ascertain if their online learning approaches and practices support their students in generating social capital via their online collaborations. This study is concerned with the ability of students to collaborate, form networks and accumulate social capital in support of their online learning studies. A qualitative research approach was selected as the research question calls for an exploration of questions about the subjective experiences of collaboration between diverse online participants. Qualitative analysis allows the inclusion of feedback from students about self-reported learning in personalised learning networks rather than focussing on data from and about activities on the formal official network. The aim of the study is to acknowledge multiple and subjective realities of students in order to gain an in-depth understanding of participants' views of social capital development in online learning.

The wide scope of the area under study requires a narrowing down of the theme to a researchable topic and a case study provides for such a contraction (Shuttleworth 2008). A case study is applied to obtain in-depth information about the interplay between students' perceptions and experiences of social capital development in an authentic online learning field such as Unisa as a bounded system. One particular fully online module at Unisa, presented during the first semester of 2015, was selected as a suitable case due to the inclusion of collaborative learning as part of the formal assessment strategy of this module. As partial fulfilment of the requirements for the module, students were required to do online group-work on myUnisa to provide solutions to problem-based assessment tasks.

A rigorous research framework was devised to ensure that the process of recruitment, data gathering and interpretation was carried out in an ethically responsible and sound manner. A system was developed to guard the privacy and anonymity of the student participants and make 
sure the research would not harm them in any way. Upon receiving ethical clearance and after permission was granted by the university to do the research, prospective student participants were recruited by phone. Reasonable care was taken during the recruitment process to make sure that a spread of students was included, i.e. a fair mix of students who had obtained distinctions, who had passed or who had failed the module.

The qualitative methodology includes a combination of focus groups and telephonic interviews. The literature guided the development of a discussion outline to be followed during the interviews in which descriptions of structural, relational and cognitive social capital are applied. The discussion outline includes questions about the type, content and frequency and results of collaborations with peers on both myUnisa and other informal platforms and social networks to gather information about opportunities for interaction and opportunities to develop shared purpose and meaning (Adler and Kwon 2002; Cummings et al. 2006; Daniel et al. 2003; Wasko and Faraj 2005). The outline provided students with the opportunity to self-report on their learning outcomes.

For the focus group interviews, students were separated according to their final results, i.e. whether they had obtained a distinction, passed or failed. In this way, successful students could not intimidate less successful ones. On completion of the focus groups, a series of indepth interviews was conducted to gather comprehensive information about the students' experiences and perceptions of their collaborations to develop an understanding of the development of social capital in online learning.

The focus groups and individual interviews generated a lot of data which were subsequently transcribed and then processed via computer-aided qualitative data analysis software to support the coding and thematic analysis and interpretation processes. Several rounds of rigorous analysis resulted in the development of a strong narrative about the student experience.

\section{RESULTS}

The research revealed that students do not rely on myUnisa only, but instead engage with other informal learning platforms, social media and service providers in customising their learning activities. The research reveals that students have divergent experiences and perceptions of these collaborations which include both offline (face-to-face) gatherings and online interactions. Online learning activities include the use of myUnisa and social media tools such as WhatsApp and StudyNotesWiki (SNW). SBW is an interactive website developed by and for Unisa students. Offline interactions include face-to-face study groups which take place at various locations, including Unisa campuses or the facilities of private service providers. These 
private service providers are not associated with or contracted to the university. The range of student interactions and collaborations are depicted in Figure 2.

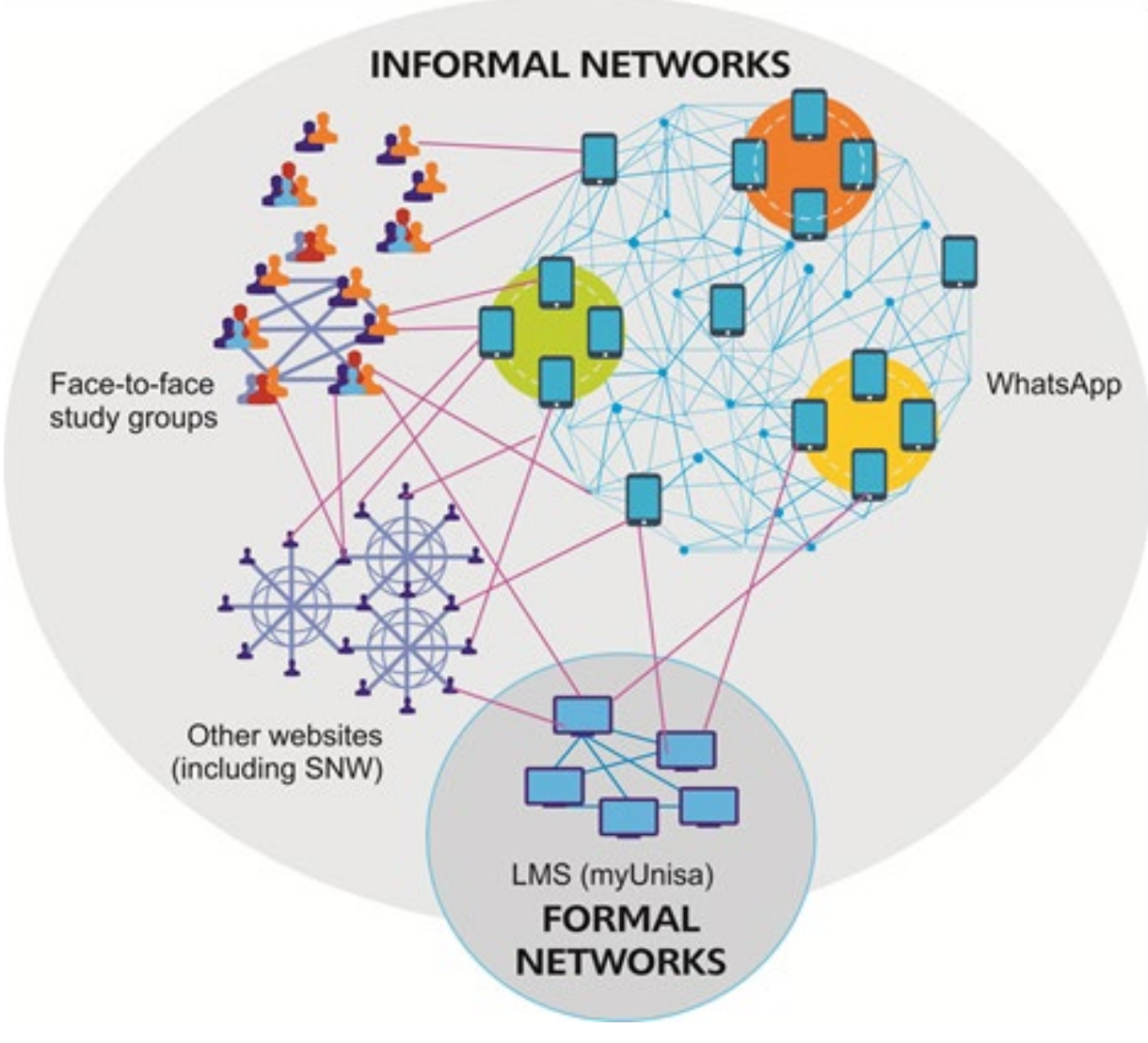

Figure 2: Illustration of different interaction modes on formal and informal learning platforms

The findings include information about a wide range of experiences and views about participation in both the formal as informal learning networks. It seems that informal collaborations between students exceed the level of mandatory collaborations on myUnisa. Some of the students expressed their dissatisfaction or frustration with the online offering of the module, particularly with regard to the required collaborative online learning part. The dissatisfaction is aptly voiced by Poppy, a young black African female, who complained that she did not understand what was expected of her in the online group work. She said "I was completely lost, at some point I was like what, what are they looking for?"

The limited participation is further illustrated by the tendency of some students to post non-constructive comments such "I agree". It created online discussions that couldn't come to fruitful conclusions. The frustration with this type of apathy is voiced by Mattheu, a black African male who said: "No, no, no, I tried that, but it didn't work for me because I just find it time wasting." 
Not all the students were dissatisfied or frustrated with their myUnisa engagements. Exceptions are illustrated by comments about positive experiences and satisfaction with online collaborations on myUnisa. The satisfied students testified that they regarded the following as benefits of working with peers on myUnisa: they could get quick access to information, knowledge transfer could take place between participating students, they were exposed to alternative viewpoints, they obtained a broader perspective, concepts were clarified amongst them, it was possible to do self-assessment, their meta-learning skills were stimulated, they developed professional skills, they experienced a decrease in feelings of isolation and they started to build confidence. Some of the above mentioned benefits are captured by Omi, an Indian female:

"And then somehow when you meet them [online] you feel more confident about yourself and what you are learning. In that sense you are not isolated with your own books but there is interaction. It can make you a better learner, more confident and get other ideas and prepare you."

The perceived benefits of doing online group work is further demonstrated by the view of Moipone, a black African female. She explained it as follows:

"So you start learning, thinking about, your way of grasping knowledge. I mean you start learning how your brain works, how you grasp different ways you can learn."

In contrast to the limited interaction on myUnisa, extensive student activities took place on the informal learning networks. The informal networks include self-initiated interactions on a range of face-to-face (offline) and online platforms, as determined by students' personal ambitions and access to resources. This demonstrate that there is an alternative learning network to what is evident on myUnisa. When myUnisa fails to meet the needs of the students, they look for substitutes and participate in self-initiated study groups and use affordable and user-friendly social media tools such as WhatsApp and SNW.

The level of face-to-face (offline) interactions between online students is a revelation. It seems that some students belonged to study groups before they registered for the online module and will continue their membership after they completed the module. Petra, a black African female explains her group came into existence when she was a first year student. She confirms that she will remain a member of the group until she graduates. She describes the development of strong bonds with these peers and calls the study group her "family". Petra elaborates on the pattern and method of her group as follows: 
“... because in my group, we helped each other a lot. We met on Saturdays from 09:00 till 16:00 because we are all working. We fought if we want to reach our goals. What we did, we delegated tasks that so that when we start the assignment, everybody had to prepare one particular question. So then we start, we know what to do. Each has their part to discuss and then we come and consolidate to agree or disagree or something and then we go home and work until we could submit."

The commitment to the study group is re-iterated by Bina, a black Africa female who explained her obligation to her group as follows: "You feel that if you were not to cooperate you will be letting them down."

Evidence showed that WhatsApp was a popular social media tool amongst the students as it afforded them with an opportunity to have quick and affordable interactions with their peers. For instance, Vuyo, a black African male explains that more students have access to WhatsApp than to personal computers and laptops. In addition, WhatsApp provides for synchronous communication between people in dyads or in larger groups. Vuyo explains that "the better thing of WhatsApp is that everybody is phoning at the same time". A critical factor is the immediacy of WhatsApp communication between large numbers of connected people. This is bolstered by the typical use of short messages, emoticons and social media acronyms and abbreviations.

Essentially, the use of a messenger application such as WhatsApp allows students access to "just-in-time" information, anytime and anywhere. This enables them to close gaps in their knowledge at critical times in their studies, i.e. before the due date of an assignment or before an examination. In this regard Jasmine, a black African female, explained the pattern of WhatsApp interactions before due dates “... it was like, especially on a Monday or a Tuesday when the assignments were due then the messages would fly around all day".

The interactions between students may be fleeting or they can be more long-standing to provide opportunities for sharing more information about their context. Poppy, a black African female, for instance explained some of the benefits of interacting on WhatsApp in the following way:

"I feel it [WhatsApp] helps sometimes [as it is better than] than being on your own and believing that you understand when you don't understand, so we get to share ideas."

It is also possible for students to meet and interact with strangers on other social networking sites such as SNW. SNW allows students to register free-of-charge and find other students who are interested in the same module/s. SNW proved to be popular among its users. Mua, a black Africa female explained that she felt that SNW allowed her the freedom to use the site according 
to her own needs. Benita said that SNW "is easier to navigate .... It feels nicer, has more colour, you make it personal, use your own avatar".

The exchanges on the platform may include quick and random requests for information or the exchanges can become more frequent and run over longer periods which provide for the development of reciprocal relations. Students explained that they would first assess the quality of another peoples' postings before selecting a prospective exchange partner or partners. Some of the students expressed their frustration with non-participants or students who fail to make beneficial postings. It seems that non-participants were easily ostracised in the SNW community.

However, SNW provide a space where active students grow close relations and strong ties and develop a sense of community with shared values of reciprocity and obligation towards one another. Benita, a white female, for instance marvelled over her membership of SNW in the following way:

"The community that I belong to is actually virtual. It is a website, called StudyNotesWiki. It was originally only for LLB, but now for BCom and I see BSc. It is fantastic. A lot of times you don't get feedback from lecturers. Then you ask questions (on SNW). Somebody will show a word that changes everything; this forum helped me a lot. This helped me through a difficult subject."

The informal network also allows students to interact with alumni, or people who are already employed. Mandla, a black African male, for instance described that he met up with a qualified person who agreed to meet him at a public library over weekends to assist him with preparing his assignments and exam preparation.

The findings show that online students move beyond the formal learning environment and integrate various interaction modes and platforms to further their learning. The students engage in both offline and online interactions across modes and platforms and develop close ties or bonds with the peers they interact frequently with, while simultaneously engaging in sporadic interactions with a diversity of students that serve as bridges across networks. Some of the cognitive benefits from collaborations with peers include the ability to share resources, receive constructive feedback, participate in mutually beneficial discussions and to be exposed to new or alternate viewpoints. There are also socio-affective advantages to collaborations in informal learning networks which include the ability to gain confidence from the interactions, develop mutual feelings of trust and reciprocity, and grow a sense of belonging and shared purpose in an emotionally supportive environment.

\section{DISCUSSION}


The integration of formal and informal learning networks, conceptualised as PLEs, include manifestations of student collaborations on both official and student-driven networks. Students look elsewhere when formal learning does not satisfy their needs. Student participation in informal structures takes place independently from the formal learning network, which means that learning takes place inside and outside the university (Attwell 2007; Van Harmelen 2006). They apply accessible and affordable interaction modes and social technologies, as demonstrated by the use of divergent offline and online collaboration modes and platforms. The wide range of self-initiated activities on informal learning networks are fast-growing and exceed the mandatory participation on formal learning networks. The opportunities for collaboration between students across the spectrum provide for the building of relations and the development of close and weak ties between students.

The concept bonding social capital is applied to describe the value of having long-term relations and strong ties with peers in an online learning environment. Bonding social capital makes it possible for students to gain a sense of belonging, build trust and establish a sense of mutual obligation. Consequently, members voluntarily exchange and share information and resources and readily encourage one another. High levels of intimacy and trust are associated with closure in the group or network, which may increase the potential for intolerance and distrust of out-group students and alternative viewpoints. Essentially bonding social capital and solidarity in groups facilitate the sharing of more of the same and/or the sanctioning of biased views.

Conversely, when students reach out to unfamiliar students in the extended networks, it becomes possible to form weak ties that create new paths or bridges. Students who hold bridging ties can be regarded as "brokers" as they facilitate information diffusion from one corner of the network to another (Sajuria et al. 2015, 710). The bridging social capital in the weak ties supports students in a significant way as it assists in closing gaps in existing knowledge bases, and provide opportunities for the development of new insights, broader perspectives and meta-learning skills.

However, not all students work equally hard in their online groups and some group members "lurk" or "loaf" on the periphery. The study showed that hard-working members resent having to support such non-participants. A social capital view may provide a useful insight into this pattern of behaviour. The concept bridging social capital is useful when looking at the "lurkers". They may not make a direct contribution to the functioning of the group, but they may well function as boundary-spanners who diffuse valuable information to other groups in the extended learning network. These "brokers" serve as bridges and carry alternate or nonredundant information that support the generation of new knowledge and stimulate new social development (Huysman and Wulf 2005, 8-9). 
The results demonstrate that it cannot be presumed that only close ties in supportive relationships have learning benefits for students. Weak ties in comprehensive networks make an important contribution in brokering new knowledge and coordinating learning benefits. In this way bonding and bridging social capital each play a complementary role in the overall facilitation of online learning.

The extensive informal contact between students demonstrate that some students need more interaction than what is currently facilitated on myUnisa, and students generally need more support from the institution. The popularity of one particular external service provider, Critical Law Studies (CLS), proves the point. Some of the students explained that they needed the supplementary tutorial services and additional learning material provided by CLS. They also emphasised their need for face-to-face contact with teaching staff. The need among these students for more support is also demonstrated by the high premium that some online students place on securing face-to-face contacts: they go to great lengths to visit Unisa facilities or the CLS campus to meet up with peers.

Students do not depend on the formal learning network, instead they establish PLEs by going out and making new connections and finding relevant resources (Cho and Shen 2013). Such bottom-up participation in informal learning network activities (Czerkawski 2016) facilitates cooperation between previously unconnected students and offers potential learning benefits to students across the spectrum. The information on self-reported learning indicate that several social capital benefits are associated with students' collaborations in PLEs, which include the opportunity to co-create knowledge, gain an improved understanding of course work, share increased levels of mutual support, experience improved levels of confidence and/or motivation, and develop self-reflective and meta-learning skills (Shen, Hiltz and Bieber 2008, 75; Brindley, Walti and Blaschke, 2009: |2). The wide-ranging informal interactions augment the activities on formal learning network (Dabbagh and Kitsantas 2012, 5).

PLEs are regarded as under the control of the learners themselves (Van Harmelen 2006) as they make plans to circumvent structural constraints (Czerniewicz, Williams and Brown 2009, 82). The development of PLEs emphasise the role of student agency in online learning. It underlines the importance self-regulation in online learning, challenging students to coordinate the options available to them and initialise and maintain meaningful collaborations with peers in order gain social capital benefits.

The above demonstrates that online practitioners need to acknowledge that students are already using various technologies according to their own needs. In an environment where information is readily available and people are just one click-away, students are increasingly exercising control over the content and relational aspects of their learning environments. They direct their learning by choosing relevant topics, times, places, media and partners according to 
their own motivation and beliefs. A lot is learned from the popularity and effectiveness of informal learning networks and the role of PLEs among diverse online students. A pedagogical shift requires the design of online learning experiences which integrate varied student interactions, support self-regulation, provide adequate and diversified student support, facilitate the development of trust and sense of community among students and generally boost student collaborative practices.

A heutagogical approach acknowledges that learning also takes place outside the formal learning environment and that a self-directed learner moves freely in and between formal and informal learning networks in a customised personal learning space. A heutagogical approach to learning design is therefore required to accommodate the needs of twenty-first century students (Blaschke 2019). Such an environment can provide for the creation of opportunities for diverse students to connect, share resources and learn together and facilitate the development of mutually beneficial learning experiences and social capital development.

\section{CONCLUSION}

The study reveals the viability of student collaborations and demonstrates how students integrate formal and informal learning collaborations in the establishment of PLEs. Special attention is given to the supportive role of collaborations in informal learning networks. PLEs provide for a range of student collaborations across networks and the development of different types of social ties, including close or strong ties between existing contacts and loose or weak ties between previously unacquainted students. Social capital theory is applied to explain how bonds between strong ties facilitate the development of bonding social capital and new pathways between weak ties people generate bridging social capital. Bonding social capital explains how close ties between students provide for learning through sharing and learning together in reciprocal and supportive relationships. Bridging social capital allows for the formation of bridges between strangers and the creation of an extended learning community in which students can close gaps in existing knowledge bases and develop broader perspectives, new insights and meta-learning skills. The study acknowledges the role of self-regulation among students in creating PLEs as they coordinate their options. This context of student learning requires the application of a heutagogical approach as an appropriate framework for designing relevant learning experiences for contemporary students.

\section{REFERENCES}

Adler, P. S. and S. W. Kwon. 2002. Social capital: Prospects for a new concept. The Academy of Management Review 27(1): 17-40. http://www.jstor.org/stable/4134367

Attwell, G. 2007. Personal learning environments - the future of eLearning? eLearning Papers 2(1): 28. 
Bharuthram, S. and C. Kies. 2013. Introducing e-learning in a South African higher education institution: Challenges arising from an intervention and possible responses. British Journal of Educational Technology 44(3): 410-420. DOI:10.1111/j.1467-8535.2012.01307.

Blaschke, L. 2019. The pedagogy-andragogy-heutagogy continuum and technology-supported personal learning environments. In Open and distance education theory revisited, 75-84. Singapore: Springer. DOI.10.1007/978-981-13-7740-2_9.

Bourdieu, P. 1986. The forms of capital. In Handbook of theory and research for the sociology of education, ed. J. Richardson, 241-258. Greenwood Press, New York.

Brindley, J.E., C.Walti and L.M. Blaschke. 2009. Creating effective collaborative learning groups in an online environment. International Review of Research in Open and Distance Learning 10 (3). DOI:10.19173/irrodl.v10i3.675.

Burt, R. S. 2004. Structural holes and good ideas. The American Journal of Sociology 110(2): 349-399.

Carceller, C., S. Dawson and L. Lockyer. 2015. Social capital from online discussion forums: Differences between online and blended modes of delivery. Australasian Journal of Educational Technology 31(2): 150-163.

Casquero, O., R. Ovelar, J. Romo, M. Benito and M. Alberdi. 2016. Students' personal networks in virtual and personal learning environments: a case study in higher education using learning analytics approach. Interactive Learning Environments 24(1): 49-67. DOI: 10.1080/ 10494820.2013.817441.

Chen, X., J. H. Choi and J. H. Yu. 2012. Applying social network analysis and social capital in personal learning environments. In Virtual professional development and informal learning via social networks, ed. V. P. Dennen and J. B. Myers, 75-92. Hershey, PA: IGI Global/Information Science Reference.

Chiu, C. H., M. H. Hsu and E. T. G. Wang. 2006. Understanding knowledge sharing in virtual communities: An integration of social capital and social cognitive theories. Science Direct: Decision Support Systems 42: 1872-1888. $\quad$ www.sciencedirect.com/science/article/pii/ S0167923606000583.

Cho, M. and D. Shen. 2013. Self-regulation in online learning. Distance Education 34(3): 290-301. DOI:10.1080/01587919.2013.835770.

Coleman, J. S. 1988. Social capital in the creation of human capital. The American Journal of Sociology, Supplement: Organizations and Institutions: Sociological and Economic Approaches to the Analysis of Social Structure 94: S95-S120.

Cummings, S., R. Heek and M. Huysman. 2006. Knowledge and learning in online networks in development: A social-capital perspective. Development in Practice 16(6): 570-586.

Czerkawski, B. 2016. Blending formal and informal learning networks for online learning. International Review of Research in Open and Distributed Learning 17(3). http://www.irrodl.org/ index.php/irrodl/article/view/2344.

Czerniewicz, L., K. Williams and C. Brown. 2009. Students make a plan: Understanding student agency in constraining conditions. ALT-J, Research in Learning Technology 17(2): 75-88.

Dabbagh, N. and A. Kitsantas. 2012. Personal learning environments, social media, and self-regulated learning: A natural formula for connecting formal and informal learning. Internet and Higher Education 15: 3-8. Doi:10.1016/j.iheduc.2011.06.002.

Daniel, B., R. A. Schwier and G. McCalla. 2003. Social capital in virtual learning communities and distributed communities of practice. Canadian Journal of Learning and Technology 29(3). https://www.cjlt.ca/index.php/cjlt/article/view/26539/19721

Dawson, S. 2010. "Seeing" the learning community: An exploration of the development of a resource for monitoring online student networking. British Journal of Educational Technology 41(5): 736-752. DOI:10.1111/j.1467-8535.2009.00970.

Downes, S. 2007. Learning networks in practice. Emerging technologies for learning. National Research Council of Canada. 
Granovetter, M. S. 1973. The strength of weak ties. American Journal of Sociology 78(6): 1360-1380.

Huysman, M. and V. Wulf. 2005. IT to support knowledge sharing in communities, towards a social capital analysis. Journal of Information Technology (2005)00: 1-12.

Kajee, L. 2008. Constructing identities in online communities of practice. Peter Lang: Oxford.

Kirschner, F. C. 2009. United brains for complex learning: A cognitive-load approach to collaborative learning efficiency. Doctoral thesis. Heerlen: Open Universiteit Nederland.

Lin, N. 1999. Building a network theory of social capital. Connections 22(1): 28-51.

Nahapiet, J. and S. Ghoshal. 1998. Social capital, intellectual capital, and the organizational advantage. The Academy of Management Review 23(2): 242-266.

Narayan, D. and L. Pritchett. 1999. Cents and sociability: Household income and social capital in rural Tanzania. Economic Development and Cultural Change 47(4): 871-897.

Ngambi, D., C. Brown, V. Bozalek, D. Gachago and D. Wood. 2016. Technology enhanced teaching and learning in South African higher education - A review of a 20 year journey. British Journal of Education Technology 47(5): 843-858. https://doi.org/10.111/bjet.12485

Oztok, M. 2012. Tacit knowledge in online learning: Community, identity, and social capital. Technology, Pedagogy and Education: 1-16. DOI: 10.1080/1475939X.2012.720414.

Oztok, M., D. Zingaro and A. Makos. 2013. Colloquium: What social capital can tell us about social presence. British Journal of Educational Technology 44(6): E203-E206.

Oztok, M., D. Zingaro, A. Makos, C. Brett and J. Hewitt. 2015. Capitalizing on social presence: The relationship between social capital and social presence. Internet and Higher Education 26: 19-24. DOI: 10.1016/j.iheduc.2015.04.002.

Putnam, R. D. 2001. Social capital: Measurement and consequences. Isuma: Canadian Journal of Policy Research 2(Spring 2001): 41-51. DOI:10.1.1.178.6284.

Queiros, D. R. and M. R. de Villiers. 2016. Online learning in a South African higher education institution: Determining the right connections for the student. International Review of Research in Open and Distributed Learning 17(5). http://www.irrodl.org/index.php/irrodl/article/view/2552

Sajuria, J., J. van Heerde-Hudson, D. Hudson, N. Dasandi and Y. Theocharis. 2015. Tweeting alone? An analysis of bridging and bonding social capital in online networks. American Politics Research 43(4): 708-738. DOI: 10.1177/1532673X1455794.

Shen, J., S. R. Hiltz and M. Bieber. 2008. Learning strategies in online collaborative examinations. IEEE Transactions on Professional Communication 51(1): 63-78.

Shuttleworth, M. 2008. Case study research design. Experiment resources. http://www.experimentresources.com/case-studyresearch-design.html

Steinfeld, C., N. B. Ellison and C. Lampe. 2008. Social capital, self-esteem, and use of online social network sites: A longitudinal analysis . Journal of Applied Developmental Psychology 29: 43445. DOI:10.1016/j.appdev.2008.07.002

Valenzuela, S., N. Park and K. F. Kee. 2009. Is there social capital in a social network site? Facebook use and college students' life satisfaction, trust, and participation. Journal of Computer Mediated Communication 14(4): 875-901. DOI: 10.1111/j.1083-6101.2009.01474.

Wasko, M. M. and S. Faraj. 2005. Why should I share? Examining social capital and knowledge contribution in electronic networks of practice. MIS Quarterly 29(1): 35-57.

Van Harmelen, M. 2006. Personal learning environments. Proceedings of the Sixth International Conference on Advanced Learning Technologies, July 5-7 2006. Washington, DC, USA: IEEE Computer Society. 